\title{
Implementation and Analysis of Mathematical Modeled Drive Train System in Type III Wind Turbines Using Computational Fluid Dynamics
}

\author{
Subash Ranjan Kabat', Chinmoy Kumar Panigrahi', Bibhu Prasad Ganthia ${ }^{1 *}$, \\ Subrat Kumar Barik', Byamakesh Nayak' \\ 1 School of Electrical Engineering, Kalinga Institute of Industrial Technology, Bhubaneswar, Odisha, 751003, \\ India \\ * Corresponding author's e-mail: jb.bibhu@gmail.com
}

\begin{abstract}
This paper is based on designing a modified rotor for a drivetrain in a Type-III wind turbine system for maximum power generation to work effectively under low and high wind speed and its variation. In this paper three drive trains are designed for the gearbox to provide regulated torque and thrust force. For time to time variation in wind speed the voltage sag and during over speed condition voltage swell problem can be solved by using this modified design. The pitch control, gear box and yaw of the wind turbine basically focused for modification. Mainly the gear box for the rotor causes sluggish motion of the rotor during low wind speed. This paper explained the design of modified rotor control for the gear box in DFIG based (Type-III) wind turbine. Also in this paper how the modified rotor system can be helpful for reactive power control highlighted with comparison with existing models. For designing MATLAB Simulink platform is taken and validated using CFD mechanical design analysis. Using these types of modified drive trains maximum power for the wind turbines is enhanced by $40-60 \%$ of its reference value.
\end{abstract}

Keywords: type III wind turbines, gear train, pitch control, gear ratio, pitch angle, yaw system, angular velocity, CFD.

\section{INTRODUCTION}

Renewable energy sources such as wind energy have grown significantly in recent years, while nonrenewable sources such as coal, petroleum, natural gas, large and medium-sized hydropower are depleting. These days energy from wind gained more attentions around world. Energy from wind using wind turbine has gained more concentration which made long blade design and also manufacturing of large horizontalaxis wind turbines has increased with a cost advantage. For the wind turbine, its unit cost will decrease with the raise of single-unit power. In the wind turbine, energy is produced by blades by means of transmitting torque. The stiffness of the blade is the major factor when designing for massive structure. The blade must also have sufficient bending stiffness to avoid blade tips from colliding with the tower under extreme wind load condition. Providing sufficient bending stiffness will increase the weight of the blade. The heaviness of blade material has a considerable influence on the operation, fatigue life and energy output of the wind turbine and also this leads to transportation problem. This invention provides modified rotor to reduce the weight of the blade and to overcome above stated problems. Since the past two decades, the milieu has witnessed a plethora of energy related issues owing to fossil fuel depletion as in case of coal and oil. Also, continuous utilization of such fuel has lead to various environmental concern. The present scenarios globally imposes the scientists and engineers to switch over to renewal energy sources (RESs) like wind and solar energy etc. [1]. In the process of extracting the electric energy out of the wind energy, there lies certain mechanical 
controls which are essential for adjusting the wind turbine structure. This comprises of gear ratio, pitch angle of turbine blades for controlling any variations in the electric energy which is generated as the output and motion control of yaw as per variation seen in wind potential. In the event of gear teeth completely fitting one with other or getting interlocked in a organized manner are said to be in a mesh. Gears in such a mesh arrangement have the ability of transmitting force and motion each to the other. This gear transmitting the force or motion is what is known as the driver gear and the gear which is coupled with this driver gear is what is known as the driven gear $[2,3]$. There is a variation in the wind energy potential, and so electric power of a wind turbine generator (WTG) generated shows much fluctuation $[4,6]$. This paper objectifies the study of behavior of the WTG functioning across variable speed with pitch angle controlling system, and turbulent wind [7]. There happens to be one more control mechanism which is based on the yaw movement capability so as to direct the wind turbine and line up itself as per direction of the wind. A wind direction sensor is used for finding out the wind direction, which is instrumental in actuating the yaw control. One of the prime function of the pitch control is to avert or stop the WT from crossing the speed limits so as to keep the operation from going beyond its mechanical limits and the power rating of the generator $[8$, 9]. In this paper, there is an attempt of presenting the comprehensive mechanical control methods which are employed for regulating the wind turbine. The control methods for the gear are identified and presented $[10,14]$.

\section{WIND TURBINE SYSTEM}

Considering the alignment of axis, the wind energy conversion system (WECS) is mainly grouped in two categories. Those are as follows:

a) As Dutch type horizontal axis wind turbines

(HAWT) are categorized into followings:

- High speed propeller WT,

- Multi blade WT.

b) The vertical axis wind turbines (VAWT) are categories as:

- Darrieus rotor type,

- Savonius rotor type.

Figure 1 illustrates the detailed internal structure of wind turbine. The equation (1) shown below is used for the calculation of the generated power of WT [2]:

$$
P_{m}=\frac{1}{2} \rho \pi R^{2} C_{P}(\lambda, \beta) V_{w}^{3}
$$

where: $\rho$ refers to the density of air, $A$ and $V_{w}$ denotes the turbine swept area and the speed of the wind respectively. $\mathrm{C}_{\mathrm{p}}$ represents the power coefficient, nonlinear in nature. The value of $\mathrm{C}_{\mathrm{p}}$ depends on the tip speed ratio $\lambda$ and blade pitch angle $\beta$ given as $\mathrm{C}_{\mathrm{p}}(\lambda, \beta)$.

The tip speed ratio $\lambda$ can be determined with the help of the equation as given below [2]:

$$
\lambda=\frac{\Omega_{\mathrm{t}} \mathrm{R}}{\mathrm{V}_{\mathrm{w}}}
$$

where: $\mathrm{R}, \Omega_{\mathrm{t}}, \mathrm{V}_{\mathrm{w}}$ refers to the radius, rotor speed and the wind velocity respectively.

The generated torque of the wind turbine $\mathrm{T}_{\mathrm{m}}$ produced can be found out using equation as follows [2]:

$$
\mathrm{T}_{\mathrm{m}}=\frac{\mathrm{P}_{\mathrm{m}}}{\Omega_{\mathrm{t}}}
$$

The $\mathrm{C}_{\mathrm{p}}$ can be found out using the equation given below [2]:

$$
c_{p}(\lambda, \beta)=c_{1}\left(\frac{c_{2}}{\lambda_{i}}-c_{3} \beta-c_{4}\right) e^{\frac{c_{5}}{\lambda_{i}}}+c_{6} \lambda
$$

where:

$$
\frac{1}{\lambda_{\mathrm{i}}}=\frac{1}{\lambda+0.08 \beta}-\frac{0.035}{1+\beta^{2}}
$$

\section{AERODYNAMIC DESIGN OF WIND TURBINE SYSTEM}

During the rotation of the wind wheel, there is a frequent change in the direction and inclination

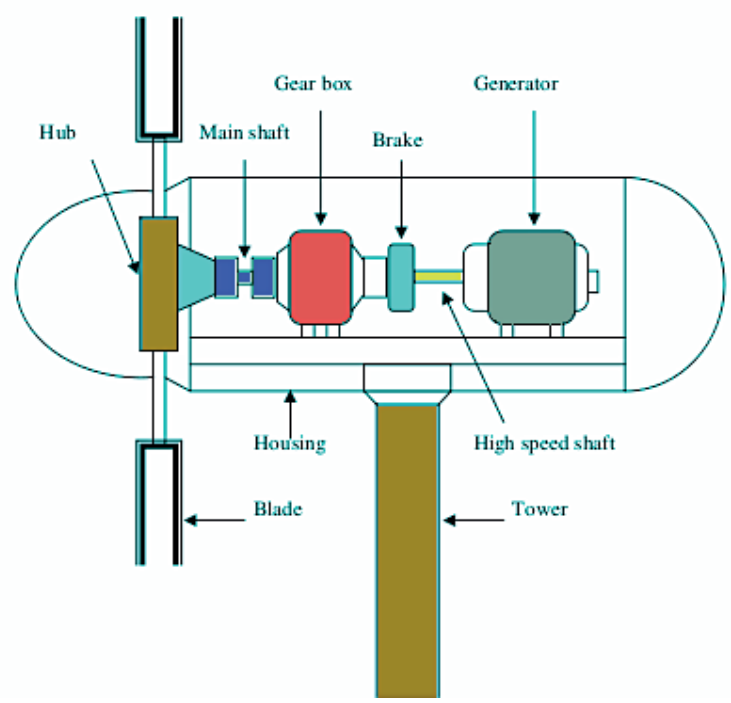

Fig. 1. Wind turbine internal design [31] 


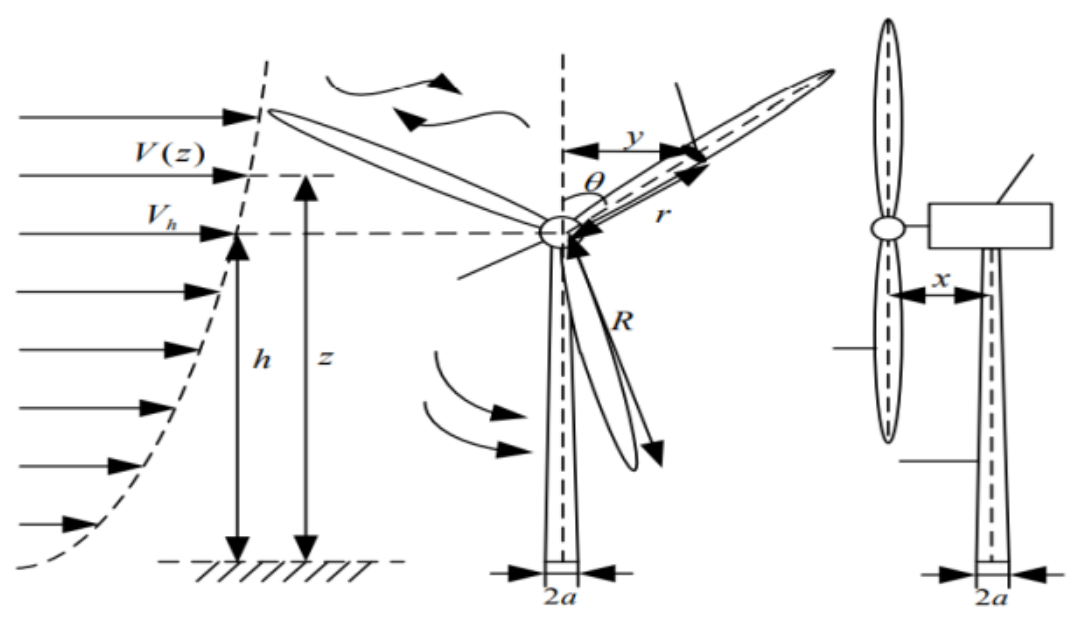

Fig. 2. Wind turbine blade turbulent of wind speed [8]

of the blade with respect to the azimuth angle in the case of horizontal axis wind turbine system. The wind shear, rapid wind and other conditions have a significant influence on the wind speed at any particular point on the blade, which is shown in Figure 2 [8].

Wind shear refers to the vertically guided wind level. Due to ground friction, which is characterized by an exponential model, it tends to increase with height [25]:

$$
\mathrm{V}(\mathrm{r}, \theta)=V_{h}\left[\frac{\mathrm{r} \cos \theta+\mathrm{h}}{\mathrm{h}}\right] \alpha
$$

where: $r$ denotes the distance between the blade portion and the root of the blade; $\theta$ denotes the azimuth angle; $h$ denotes the hub height measured from the ground as the base; $V_{h}$ denotes the hub wind speed; and $\alpha$ denotes the wind shear coefficient.

The tower's obstruction of the air flow causes a variation in wind speed known as the tower shadow effect. The possible flow principle can be used to quantify the effect of the tower on wind speed in the case of an upwind wind turbine (WT) [19].

$$
\mathrm{V}(\mathrm{x}, \mathrm{y})=V_{h}+V_{0} a^{2} \frac{y^{2}-x^{2}}{\left(x^{2}+y^{2}\right)^{2}}
$$

where: $a$ refers to the tower radius; $V_{0}$ refers to the spatial average wind speed; $x$ refers to the distance from the wind wheel's rotation plane to the tower axis; $y$ refers to the lateral distance between the element of the blade and the tower axis, expressed as $y_{r}=\sin \theta$.

The spatial average wind speed $V_{0}$ and the hub wind speed $V_{h}$ well satisfies the equation given below [19]:

$$
V_{0}=V_{h}\left[1+\frac{\alpha(\alpha-1) R^{2}}{8 h^{2}}\right]=\mathrm{m} V_{h}
$$

where: $m$ refers to the notation for constant and $\mathrm{R}$ refers to the radius of the wind wheel.

Referring to Figure 2, the distance $x$ from the wind wheel's rotation plane to the tower axis has a fixed value, whereas a variation is noticed in the lateral distance $y$ from the element of the blade to the tower axis according to the variation of azimuth angle $\theta$, therefore (2) can be expressed as equation (9) [19]:

$$
\mathrm{V}(\mathrm{r}, \theta)=V_{h}+V_{h} m a^{2} \frac{r^{2} \sin ^{2} \theta-x^{2}}{\left(r^{2} \sin ^{2} \theta+x^{2}\right)^{2}}
$$

Usually, wind shear and tower shadow work simultaneously. In case of the top half swept area of the wind wheel, the wind speed model can be visualized using (1). On the top half swept wind area, the azimuth angle $\theta$ is such that it it lies between $\frac{2 n \pi-\pi}{2}$ and $\frac{2 n \pi-\pi}{2}$. In other words, $\theta \in \pm\left[\frac{2 \mathrm{n} \pi-\pi}{2}, \frac{2 \mathrm{n} \pi+\pi}{2}\right]$. On the lower half swept area of the wind wheel, the model of the wind speed is represented in the form of the equation as given below [19]:

$$
\mathrm{V}(\mathrm{r}, \theta)=V_{h}\left[\frac{\mathrm{r} \cos \theta+\mathrm{h}}{\mathrm{h}}\right] \tau\left[1+m a^{2} \frac{r^{2} \sin ^{2} \theta-x^{2}}{\left(r^{2} \sin ^{2} \theta+x^{2}\right)^{2}}\right]
$$

Observing the wind speed model, it is evident that the wind speed model undergoes a periodic variation with respect to the change in azimuth angle of the wind wheel because of the impact of wind shear and tower shadow effect. As a result, there is a change in WT's aerodynamic load in each complete wind wheel's rotation, which means the WT's aerodynamic load pulsates with the wind wheel's rotation frequency (1P). Wind shear and 
tower shadow effect not only causes $1 \mathrm{P}$ aerodynamic load pulsation but also have a certain influence on WT aerodynamic torque. So as to unable the analysis of the relationship between aerodynamic torque and wind speed model, the concept of equivalent wind speed model was introduced in [20]. It has to keep the aerodynamic torque fixed or constant and the $\mathrm{V}_{\mathrm{eq}}(\theta)$ wind speed model is actuated with $\mathrm{V}(\mathrm{r}, \theta)$ actual wind speed based on the spatial distribution. It is defined as [25]:

$$
\mathrm{V}_{\text {eq }}(\theta)=\mathrm{V}_{\text {eq0 }}+\mathrm{V}_{\text {eqws }}(\theta)+\mathrm{V}_{\text {eqts }}(\theta)(11)
$$

where: $V_{\mathrm{eq}}(\theta)$ denotes the equivalent wind speed at the hub core, $\mathrm{V}_{\text {eqws }}(\theta)$ denotes the equivalent wind speed due to the influence of wind shear on the three blades of the WT and $\mathrm{V}_{\text {eqts }}(\theta)$ denotes the equivalent wind speed due to the impact of the tower shadow effect on the three blades of the WT.

These are expressed as given below [25]:

$$
\mathrm{V}_{\mathrm{eq} 0}=\mathrm{V}_{\mathrm{h}}
$$

$\mathrm{V}_{\text {eqws }}(\theta)=\mathrm{V}_{\mathrm{h}}\left[\frac{\alpha(\alpha-1)^{2}}{8}\left(\frac{R}{h}\right)^{2}+\frac{\alpha(\alpha-1)(\alpha-2)}{60}\left(\frac{R}{h}\right)^{3} \cos 3 \theta\right]$

$\mathrm{V}_{\text {eqts }}(\theta)=\frac{\mathrm{mV}_{\mathrm{h}}}{3 \mathrm{R}^{2}} \sum_{i=1}^{3}\left[\frac{a^{2}}{\sin ^{2} \theta_{i}} \ln \left(\frac{R^{2} \sin ^{2} \theta_{i}}{x^{2}}+1\right)-\frac{2 a^{2} R^{2}}{R^{2} \sin ^{2} \theta_{i}+x^{2}}\right]$

The aerodynamic torque of the WT is defined as considering the equivalent model for the wind speed is [25]:

$$
\mathrm{T}(\theta)=T_{0}\left[1+2 \frac{1-m}{m}+\frac{2}{V_{0}}\left[\mathrm{~V}_{\text {eqws }}(\theta)+\mathrm{V}_{\text {eqts }}(\theta)\right]\right]
$$

\section{MECHANICAL DRIVE TRAIN GEAR SYSTEM}

The turbine acts as a primary component in the energy transfer mechanism for the entire wind power generation system. Its primary purpose is to convert the kinetic energy of air flowing through the turbine into mechanical energy, which is then used to drive the generator shaft. The conversion of energy from the wind domain to the mechanical domain is a multidisciplinary process that involves aerodynamics, fluid mechanics, and other disciplines. For simplicity and ease, it is usually defined as follows [3]:

$$
\mathrm{P}_{\mathrm{w}}=\frac{1}{2} \rho_{\mathrm{air}} \pi \mathrm{R}^{2} \mathrm{C}_{\mathrm{p}} v^{3}
$$

Setting up the aerodynamic model is mainly for the purpose of supplying mechanical torque to the shafting model. As a result, the torque equivalent equation is given below [3]:

$$
T_{w}=\frac{P_{w}}{\omega_{t}}
$$

where: $P_{w}$ refers to the mechanical power which obtained from the wind; $T_{w}$ refers to the mechanical torque which is transformed from the energy which is extracted from the wind by the turbine; $\omega_{\mathrm{t}}$ is defined as the turbine angular speed; $\rho$ is the defined as the density of the air; $\mathrm{R}$ refers to the wind wheel radius; refers to the corresponding speed of the wind. $\mathrm{C}_{\mathrm{p}}$ is known as the wind energy utilization coefficient, a function of both the tip speed ratio $\lambda$ and the pitch angle $\beta$.

Modeling of the fitting curve of $\mathrm{C}_{\mathrm{p}}$ in the form of the equation is given below [3]:

$$
\mathrm{C}_{\mathrm{p}}=0.22\left(\frac{116}{\lambda_{1}}-0.4 \beta-5\right) e \frac{-12 \cdot 5}{\lambda_{1}}
$$

In the above equation, $\lambda$ refers to tip speed ratio. The shafting equivalent and modeling methods differ in many ways which brings about variation in the shafting models of DFIG-based WTs. Broadly, these are of two types; the block model employing 2 mass and the block model employing 3 masses. Both of these models have mechanical torque $T_{w}$ and electromagnetic torque $T_{e}$ in the form of their input variables. The block model employing 2 mass is more preferable by the research scholars these days. The rotor, low-speed drive shaft, high-speed drive shaft, and generator, among other components, make up the mechanical shaft assembly of the DFIG based WT. By using the two-mass block form, the mass block is the turbine itself, and the pair generator and gear box are considered another mass block.

The motion equations shows in equation 19-22 [28] for the 2-mass block model of shafting is defined as in Figure 3 [28].

$$
\begin{aligned}
2 \mathrm{H}_{\mathrm{t}} \frac{d \omega_{t}}{d t} & =T_{w}-T_{\text {shaft }}-D_{t} \omega_{t} \\
2 \mathrm{H}_{\mathrm{g}} \frac{d \omega_{g}}{d t} & =T_{\text {shaft }}-T_{e}-D_{g} \omega_{g} \\
\frac{d \theta_{s}}{d t} & =\omega_{0}\left(\omega_{t}-\omega_{g}\right) \\
T_{\text {shaft }} & =K_{s} \theta_{s}+D_{s}\left(\omega_{t}-\omega_{g}\right)
\end{aligned}
$$

where: $\mathrm{H}_{\mathrm{t}}$ refers to the turbine's inertia time constant, refers to the generator's inertia time constant; $\omega_{\mathrm{t}}$ refers to the turbine speed, $\omega_{\mathrm{g}}$ refers to the speed of the generator; $K_{s}$ refers to the shaft's stiffness coefficient, $\theta_{s}$ refers to the relative angular displacement between the two masses, i.e. the shaft's 


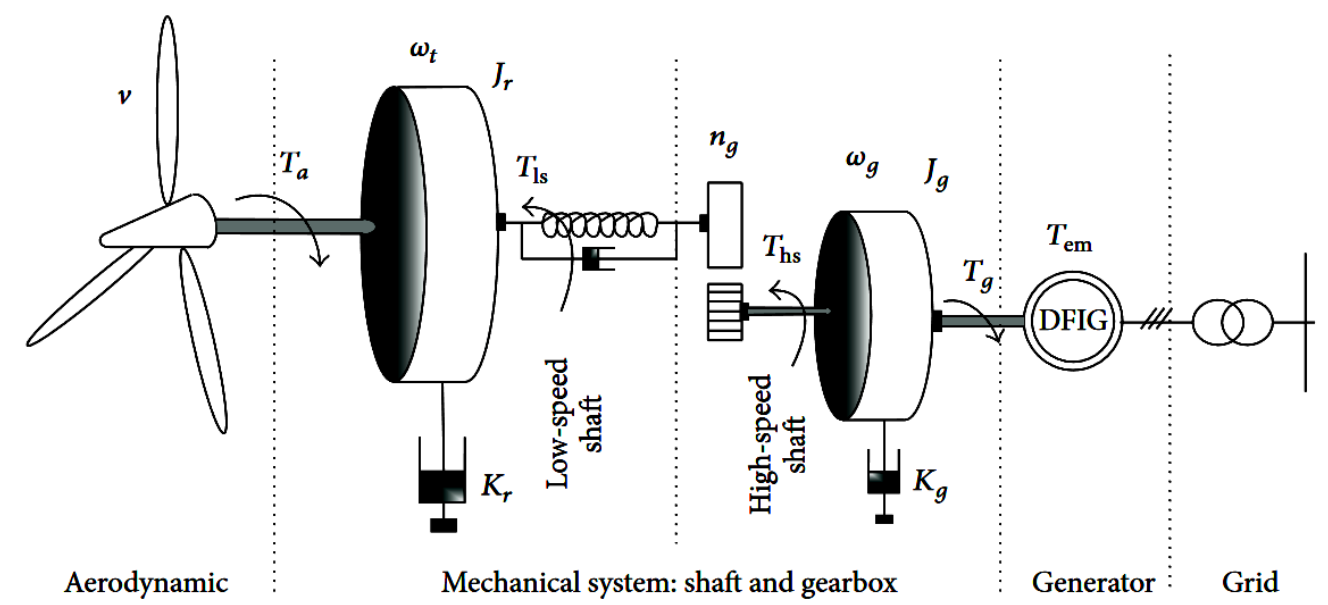

Fig. 3. Mass block model of wind turbine [28]

torsional angle; $D_{t} D_{g}$ and $D_{s}$ refers to the transmission shaft's torsional damping coefficient, turbine rotor's damping coefficient, and generator rotor's damping coefficient respectively; $T_{w}$ is the turbine's input mechanical torque; $\mathrm{T}$ refers to the mechanical torque output and $T_{e}$ refers to the generator's electromagnetic torque.

Wind turbines have recently been developed to harness the kinetic energy of the wind and transform it to electrical energy. A horizontal axis wind turbine is the most common kind of wind turbine used for electricity generation (HAWT). Figure 4 [29] shows the DFIG model with the above-mentioned internal gear system structure. Wind turbines and their constituent parts, such as blades, are rapidly growing in number. The sum of reinforcing grows in a logarithmic progression as the blades get bigger. Using rotor/blade supporting means, the size and expense of blades can be minimized. Because of the circular cross-section of traditional blades, the root area does not add to wind turbine output and, in practice, decreases it somewhat due to wind resistance. Low cambered airfoils can also be used in the outward area of blades with minimal L/D due to aero elastic influences. The proposed technology introduces a multi-stage blade rotor that is specifically designed for horizontal axis wind turbines. This blade assembly extends radially from a central core, with each joined blade assembly consisting of a first blade and a second blade or more blades in separate planes linked by one or more brace systems.

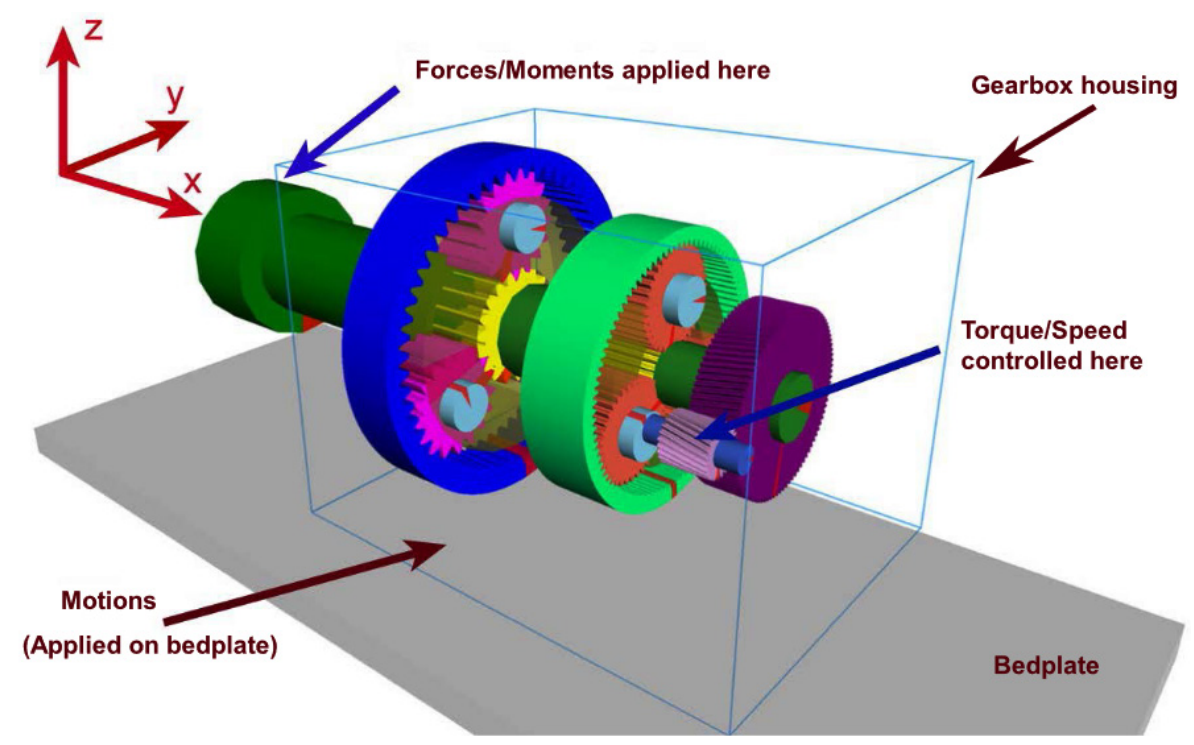

Fig. 4. DFIG model with internal gear system structure [29] 


\section{CFD MECHANICAL DESIGN FOR WIND TURBINE MODEL}

In present work an attempt is made to investigate the lift and drag forces for different Reynolds number and angle of attack for wind turbine blade. In present work NACA 0012 airfoil profile is considered for analysis of wind turbine blade. The lift and drag forces are calculated at different angle of attack varying from $0^{\circ}$ to $80^{\circ}$ for Reynolds number from 10,000 to 800000 by Computational Fluid Dynamics (CFD) software ANSYS FluentTM analysis. CFD uses computers to model air or fluid flows in a qualitative and often even quantitative way for dynamic rotational movement of the rotor turbines:

- Numerical methods,

- Statistical modeling (partial differential equations) (discretization and solution techniques) is used in this model for the validation of the system shown in Figure 5 and 7.

These dynamics of wind turbine illustrates that the wind speed and the rotor speed should be equilibrium to maintain the standard operation under normal condition of wind speed. The Figure 8 shown below is the mechanical design of the modified DFIG type-III WT model with gearbox. Figure 9 shown below illustrates the schematic model for both CAD and MATLAB designs showing gearboxes.

Table 1. Parameters for the gearbox drive train of different speed shafts

\begin{tabular}{|l|c|c|c|}
\hline \multirow{2}{*}{\multicolumn{1}{|c|}{ Parameters }} & \multicolumn{3}{c|}{ Drivetrain } \\
\cline { 2 - 4 } & $\mathrm{A}$ & $\mathrm{B}$ & $\mathrm{C}$ \\
\hline Rated speed (rpm) & 515 & 1836 & 1680 \\
\hline Generator type & PMG & DFIG & DFIG \\
\hline Number of poles & 10 & 4 & 4 \\
\hline Grid voltage (V) & 690 & 690 & 690 \\
\hline Frequency (Hz) & 60 & 60 & 60 \\
\hline Mutual inductance (Lm) & 0.32 & 3.0 & 3.0 \\
\hline Stator leakage reactance (Ls) & 0.64 & 0.1 & 0.1 \\
\hline Line inductance & 0.09 & 0.09 & 0.1 \\
\hline
\end{tabular}

\section{CFD DESIGN RESULTS}

The parameters for the gearbox drive train of different speed shafts are given in Table 1 and the parameters for drive trains with different stages are shown in Table 2. Figure 10 and 11 shows wind speed contour analysis of DFIG based wind turbine and upper turbulence analysis of wind turbine system exposed to air. Figure 12 shown illustrates that torque ratios for the various drivetrains designs of modified DFIG based T-III wind turbine with intermediate shaft, low speed shaft and high speed shafts with different gearbox ratios:

- $\mathrm{TP}=\mathrm{n}-1 \sum \mathrm{i}=112(\mathrm{P}(\mathrm{Vi}+1)+\mathrm{P}(\mathrm{Vi})) \times \mathrm{f}(\mathrm{Vi}<$ $\mathrm{V}<\mathrm{Vi}+1) \times 8760$

- $\mathrm{TF}=\mathrm{n}-1 \sum \mathrm{i}=112(\mathrm{~T}(\mathrm{Vi}+1)+\mathrm{T}(\mathrm{Vi})) \times \mathrm{f}(\mathrm{Vi}<$ $\mathrm{V}<\mathrm{Vi}+1) \times 8760$

where: $\mathrm{P}(\mathrm{Vi})$ and $\mathrm{T}(\mathrm{Vi})$ are the power and thrust force at the wind speed of $\mathrm{Vi}$

Table 3 illustrates the calculation of thrust torque, thrust power and thrust force of the wind rotor of various drive trains. Considering the Table 3, it is concluded that the modified rotor in Type-III wind turbine system can use these three types of drive train gearboxes for maximum torque and maximum power production. The capacity enhanced by $40-60 \%$ of previous models of DFIGs.

Table 2. Parameters for drive trains with different stages

\begin{tabular}{|c|c|c|c|c|}
\hline \multirow{2}{*}{\multicolumn{2}{|c|}{ Parameters }} & \multicolumn{3}{|c|}{ Drivetrain } \\
\hline & & A & B & C \\
\hline \multicolumn{2}{|c|}{ Rated power (MW) } & 3 & 3 & 2 \\
\hline \multicolumn{2}{|c|}{ Gearbox ratio } & $1: 34$ & $1: 115$ & $1: 92$ \\
\hline \multicolumn{2}{|c|}{ Gearbox stages } & 2 & 3 & 3 \\
\hline \multirow{3}{*}{ Gearbox } & Stage 1 & Planetary & Planetary & Planetary \\
\hline & Stage 2 & Planetary & Planetary & Parallel \\
\hline & Stage 3 & -- & Parallel & Parallel \\
\hline \multicolumn{2}{|c|}{ Min. rotor speed (rpm) } & 8.6 & 8.6 & 10.8 \\
\hline \multicolumn{2}{|c|}{ Rated rotor speed (rpm) } & 14.8 & 16.1 & 16.0 \\
\hline \multicolumn{2}{|c|}{ Max. rotor speed (rpm) } & 18.4 & 18.4 & 19.1 \\
\hline
\end{tabular}

Table 3. Speed variation and parametric analysis for various drive trains with different stages

\begin{tabular}{|c|c|c|c|c|c|c|c|c|c|}
\hline Drive Trains & \multicolumn{3}{|c|}{ Drive train A } & \multicolumn{3}{|c|}{ Drive train $B$} & \multicolumn{3}{|c|}{ Drive train $\mathrm{C}$} \\
\hline Speed regulation & $\begin{array}{c}\text { Thrust } \\
\text { torque } \\
(\mathrm{Nm})\end{array}$ & $\begin{array}{l}\text { Thrust } \\
\text { force } \\
(\mathrm{kN})\end{array}$ & $\begin{array}{l}\text { Thrust } \\
\text { power } \\
(\mathrm{MW})\end{array}$ & $\begin{array}{l}\text { Thrust } \\
\text { torque } \\
(\mathrm{Nm})\end{array}$ & $\begin{array}{l}\text { Thrust } \\
\text { force } \\
(\mathrm{kN})\end{array}$ & $\begin{array}{l}\text { Thrust } \\
\text { power } \\
(\mathrm{MW})\end{array}$ & $\begin{array}{c}\text { Thrust } \\
\text { torque } \\
(\mathrm{Nm})\end{array}$ & $\begin{array}{c}\text { Thrust } \\
\text { force }(k N)\end{array}$ & $\begin{array}{l}\text { Thrust } \\
\text { power } \\
(\mathrm{MW}) \\
\end{array}$ \\
\hline Low speed & 1.72 & 142.5 & 1.35 & 1.725 & 142.7 & 1.39 & 1.732 & 142.8 & 1.40 \\
\hline $\begin{array}{l}\text { Intermediate speed } \\
\text { (nominal) }\end{array}$ & 1.71 & 142.0 & 1.45 & 1.720 & 142.1 & 1.47 & 1.725 & 142.2 & 1.49 \\
\hline High speed & 1.70 & 140.6 & 1.56 & 1.705 & 140.7 & 1.562 & 1.69 & 140.9 & 1.57 \\
\hline
\end{tabular}




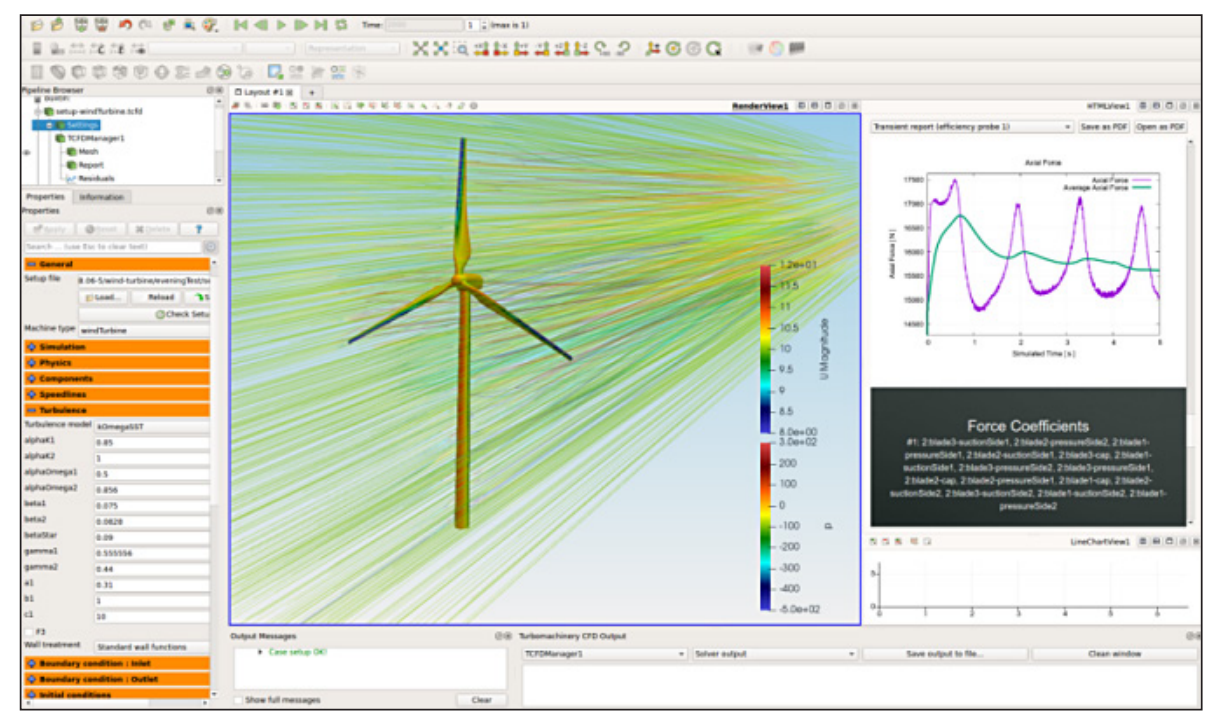

Fig. 5. CFD design of wind turbine for rotational study

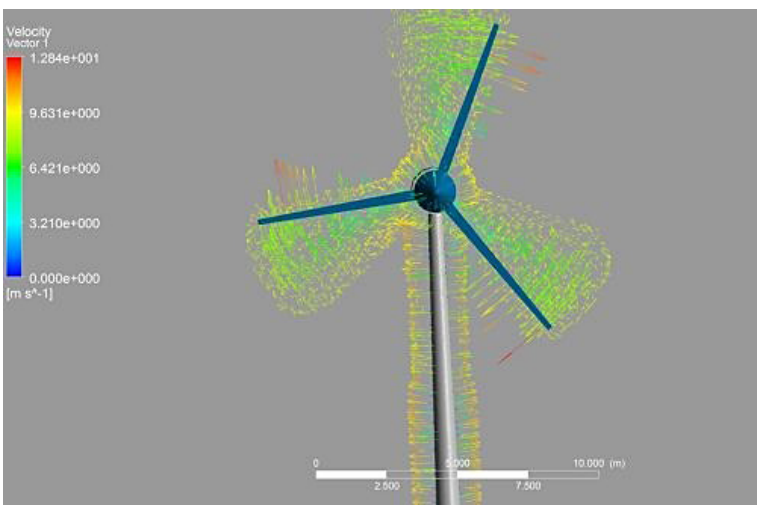

Fig. 6. CFD design analysis of DFIG based wind turbine system (front view)

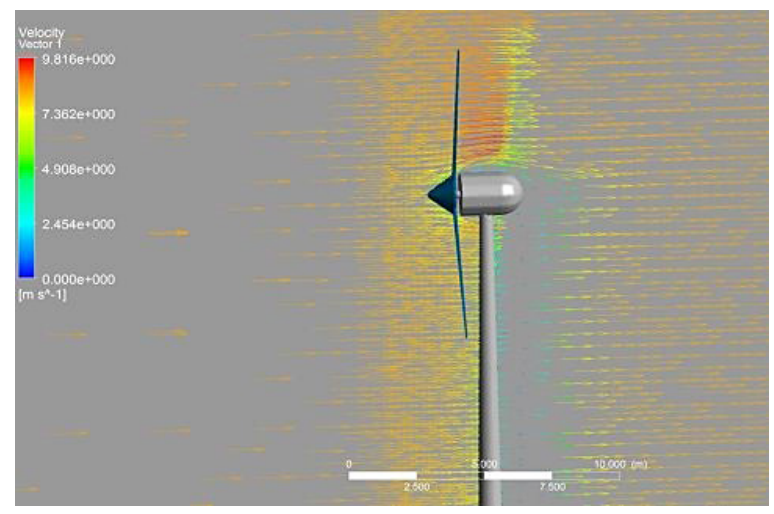

Fig. 7. CFD design analysis of DFIG based wind turbine system (translational view)

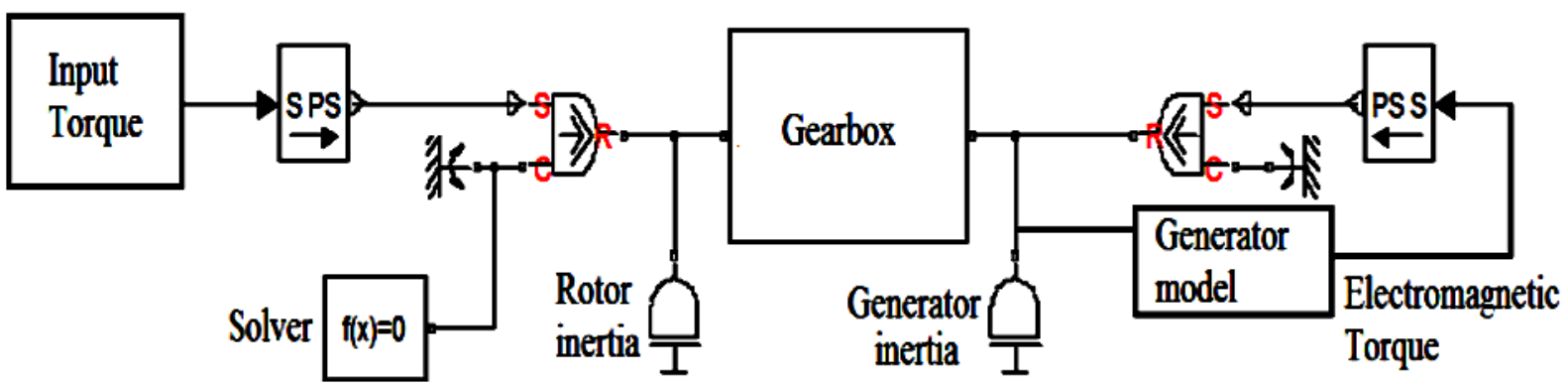

Fig. 8. Wind turbine design using MATLAB Simulink [1]

\section{CONCLUSION}

Using these modified drive trains in rotor control for the gear box in DFIG based (Type-III) wind turbine can be useful for achieving maximum power and torque for nominal wind speed operations. Also, this paper can be helpful for reactive power control highlighted with comparison with existing models. The better active and reactive power is results make the system sustainable and efficient. For designing MATLAB Simulink platform is taken and validated using CFD mechanical design analysis. The proposed model designs are studied for various gearbox ratios to get better torques for the drivetrain and it is being studied with various speed shafts. The active and reactive powers are also compares for the proposed technique to define its quality and novelty. 


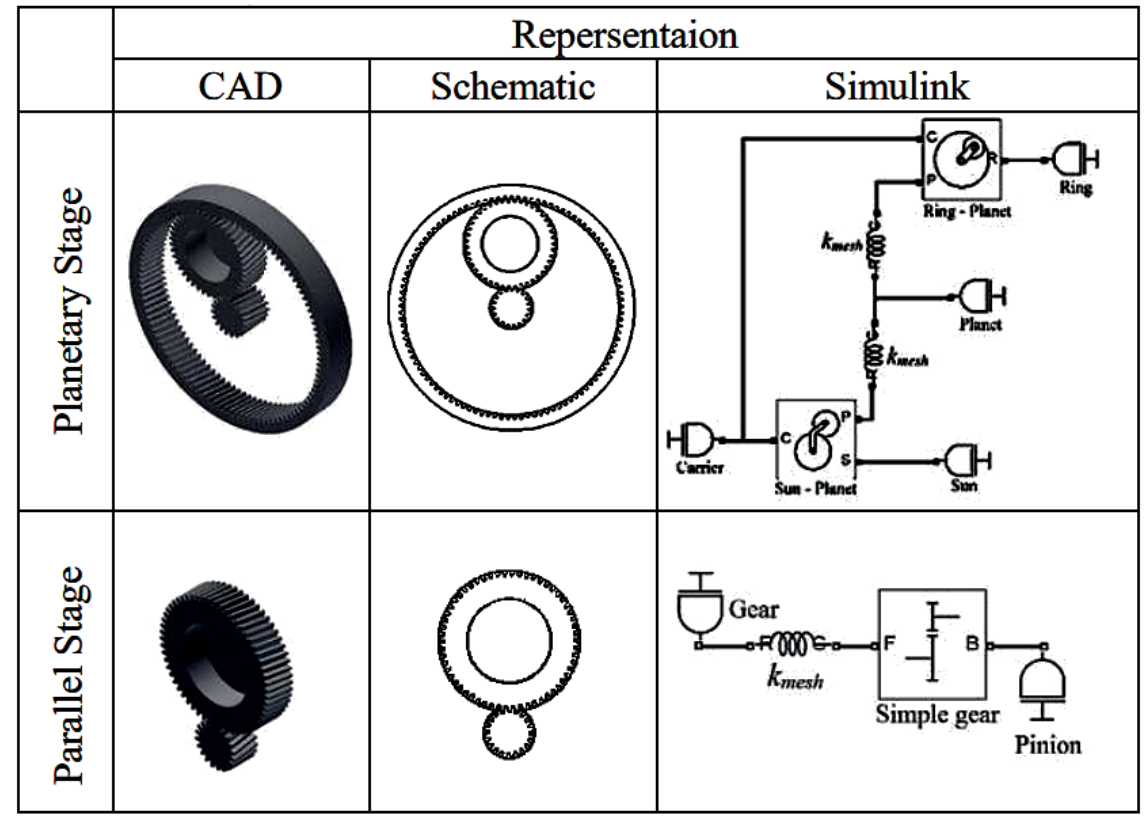

Fig. 9. Gearbox design using MATLAB Simulink

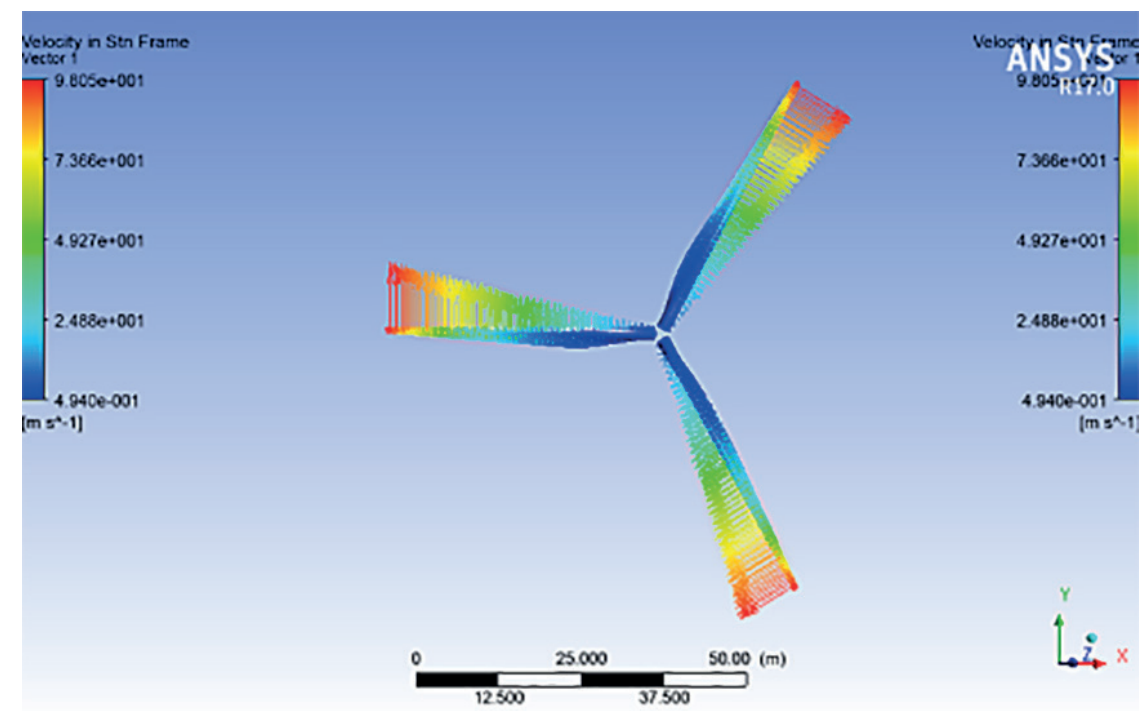

Fig. 10. Wind speed contour analysis of DFIG based wind turbine exposed to air
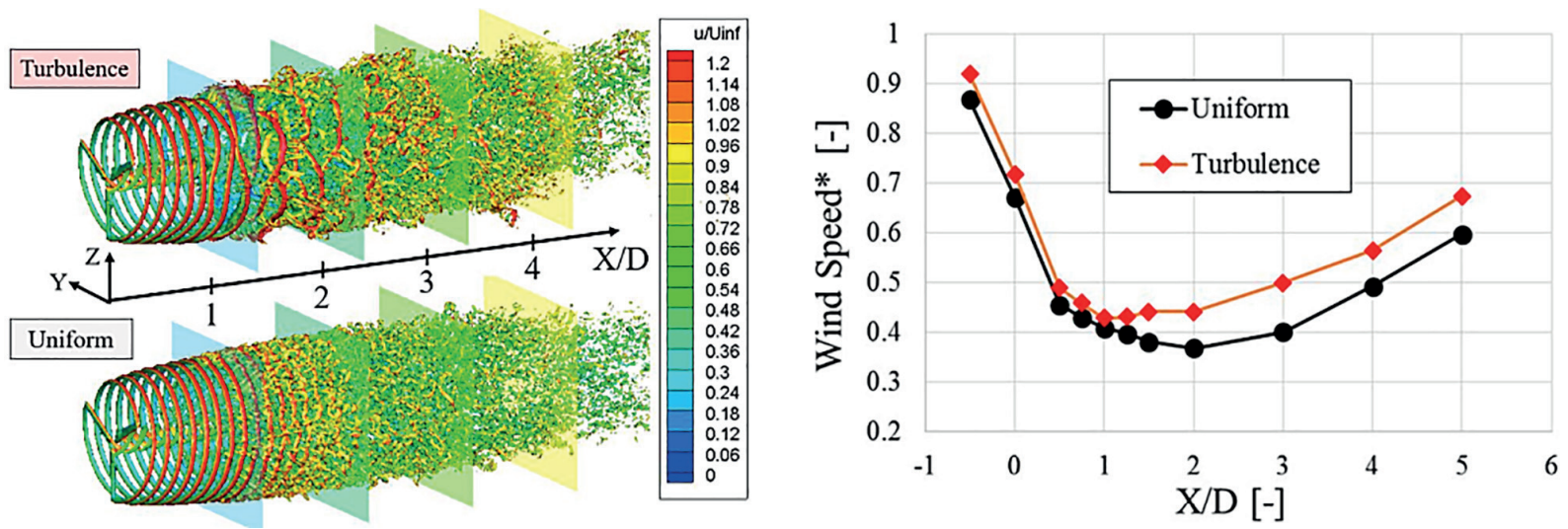

Fig. 11. Upper turbulence analysis of wind turbine system exposed to air 


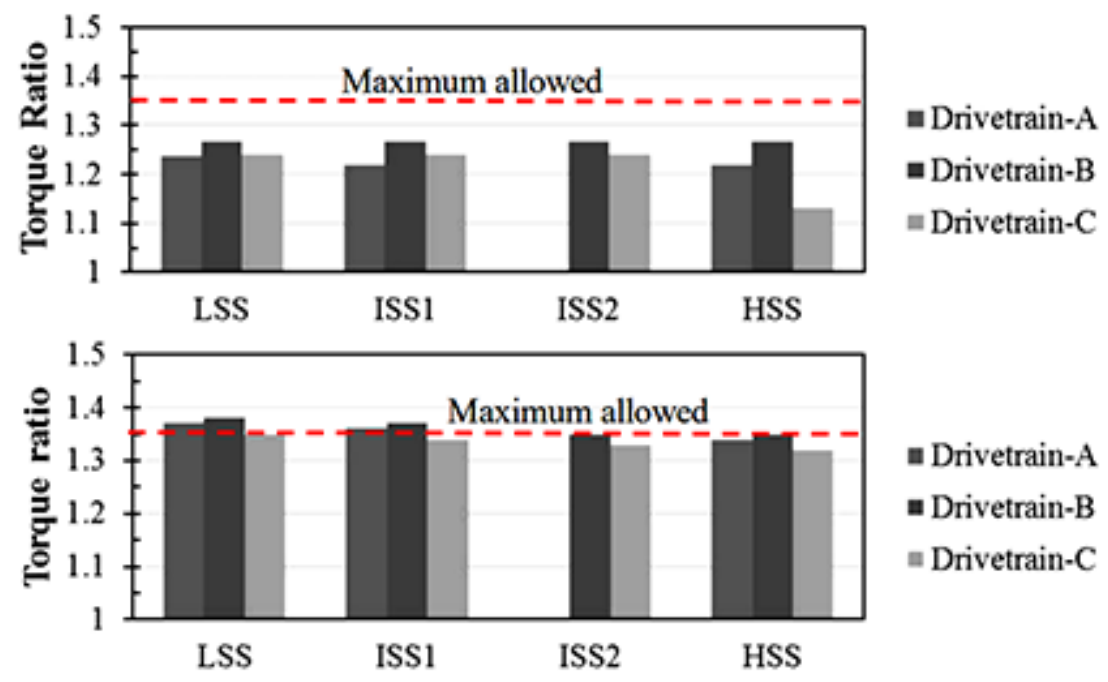

Fig. 12. Torque ratios for the various drive trains

The above comparative analysis illustrated that the proposed technique could be implemented in wind turbine system for both stand alone and grid integrated mode for high efficiency and maximum output power.

\section{REFERENCES}

1. Medeiros Rocha M., Patrocinio da Silva J., das Chagas Barbosa de Sena F. Simulation of a fuzzy control applied to a variable speed wind system connected to the electrical network. IEEE Lat Am Trans. 2018; 16(2): 521-526. Available from: https://ieeexplore.ieee.org/document/8327408

2. Ganthia B.P., Barik S.K. Steady-state and dynamic comparative analysis of PI and fuzzy logic controller in Stator voltage oriented controlled DFIG fed wind energy conversion system. J Inst Eng (India) Ser B. 2020; 101(3): 273-286. Available from: http://dx.doi.org/10.1007/s40031-020-00455-8

3. Ganthia B.P., Barik S.K., Nayak B. Shunt connected FACTS devices for LVRT capability enhancement in WECS. Eng technol Appl Sci Res. 2020; 10(3): 5819-5823. Available from: https://etasr. com/index.php/ETASR/article/view/3560

4. Ganthia B.P., Mohanty S., Rana P.K., Sahu P.K. Compensation of voltage sag using DVR with PI controller. In: 2016 International Conference on Electrical, Electronics, and Optimization Techniques (ICEEOT). IEEE 2016, 2138-2142.

5. Ganthia B.P., Kumar Rana P., Patra T., Pradhan R., Sahu R. Design and analysis of gravitational search algorithm based TCSC controller in power system. Mater Today. 2018; 5(1): 841-847. Available from: https://www.sciencedirect.com/science/article/pii/ S221478531732401X
6. Honrubia-Escribano A., Jimenez-Buendia F., Gomez-Lazaro E., Fortmann J. Field validation of a standard type 3 wind turbine model for power system stability, according to the requirements imposed by IEC 61400-27-1. IEEE trans energy convers. 2018; 33(1): 137-145. Available from: https:// ieeexplore.ieee.org/document/8006301

7. Sun L., Peng C., Hu J., Hou Y. Application of type 3 wind turbines for system restoration. IEEE Trans Power Syst. 2018; 33(3): 3040-3051. Available from: https://ieeexplore.ieee.org/document/8067521

8. Guest E., Jensen K.H., Rasmussen T.W. Sequence domain harmonic modeling of type-IV wind turbines. IEEE Trans Power Electron. 2018; 33(6): 4934-4943. Available from: https://ieeexplore. ieee.org/document/8000361

9. Ganthia B.P., Barik S.K., Nayak B. Low voltage ride through capability enhancement using series connected fact devices in wind energy conversion system. Edu.my. [cited 2021 Dec 9]. Available from: https://jestec.taylors.edu.my/Vol\%2016\%20 issue $\% 201 \% 20$ February\%202021/16_1_26.pdf

10. Goksu O., Altin M., Fortmann J., Sorensen P.E. Field validation of IEC 61400-27-1 wind generation type 3 model with plant power factor controller. IEEE trans energy convers. 2016; 31(3): 11701178. Available from: https://ieeexplore.ieee.org/ document/7438835

11. Hussein D.N., Matar M., Iravani R. A wideband equivalent model of type-3 wind power plants for EMT studies. IEEE trans power deliv. 2016; 31(5): 2322-2331. Available from: https://ieeexplore. ieee.org/document/7448463

12. Joshi Y., Maherchandani J.K., Yadav V.K., Jangid R., Vyas S., Sharma S.S. Performance improvement of standalone battery integrated hybrid system. In: 
2021 7th International Conference on Electrical Energy Systems (ICEES). IEEE 2021, 250-255.

13. Joshi B., Maherchandani J.K., Chhipa A.A. Comparison between open and closed loop battery charging technique for lithium-ion battery. In: 2021 7 th International Conference on Electrical Energy Systems (ICEES). IEEE 2021, 150-155.

14. Van T.L., Nguyen T.H., Lee D.C. Advanced pitch angle control based on fuzzy logic for variablespeed wind turbine systems. IEEE trans energy convers. 2015; 30(2): 578-587. Available from: https://ieeexplore.ieee.org/document/7018971

15. Daniela H.A., D. MI. Type IV Wind Turbine Model. Dtu.dk. [cited 2021 Dec 9]. Available from: https://backend.orbit.dtu.dk/ws/files/102281784/ Type_IV_wind_turbine_model.pdf

16. Shrimali B., Maherchandani J.K., Chhipa A.A. Vehicle to grid system integration for frequency regulation of renewable based microgrid. In: 2021 International Conference on Sustainable Energy and Future Electric Transportation (SEFET). IEEE 2021, 1-6.

17. Jangid R., Maherchandani J.K., Joshi R.R., Das Vairagi B. Development of advance energy management strategy for standalone hybrid wind \& PV system considering rural application. In: 2019 International Conference on Smart Systems and Inventive Technology (ICSSIT). IEEE 2019, 1217-1223.

18. Zerouali M., Boutouba M., Ougli A.E., Tidhaf B. Control of variable speed wind energy conversion systems by fuzzy logic and conventional P\&O. In: 2019 International Conference on Intelligent Systems and Advanced Computing Sciences (ISACS). IEEE 2019, 1-5.

19. Ferrari M., Orendorff M., Smith T., Buckner M.A. Open-code, real-time emulation testbed of gridconnected type-3 wind turbine system with hardware validation. In: 2019 IEEE Applied Power Electronics Conference and Exposition (APEC). IEEE 2019, 66-70.

20. Zaki Diab A.A., Hassan M.S., Shoyama M. Modified adaptive sliding mode control for sensorless direct-drive permanent magnet synchronous generator wind turbines based on fuzzy logic control. In: 2019 IEEE 4th International Future Energy Electronics Conference (IFEEC). IEEE 2019, 1-8.
21. Eisa S.A., Stone W., Wedeward K. Mathematical modeling, stability, bifurcation analysis, and simulations of a type-3 DFIG wind turbine's dynamics with pitch control. In: 2017 Ninth Annual IEEE Green Technologies Conference (GreenTech). IEEE 2017, 334-341.

22. Ganthia B.P., Agarwal V., Rout K., Pardhe M.K. Optimal control study in DFIG based wind energy conversion system using PI \& GA. In: 2017 International Conference on Power and Embedded Drive Control (ICPEDC). IEEE 2017, 343-347.

23. Muljadi E., Gevorgian V., Hoke A. Energy storage opportunities and capabilities of a type 3 wind turbine generator. In: 2016 IEEE Energy Conversion Congress and Exposition (ECCE). IEEE 2016, 1-5.

24. Siraj K., Siraj H., Nasir M. Modeling and control of a doubly fed induction generator for grid integrated wind turbine. In: 2014 16th International Power Electronics and Motion Control Conference and Exposition. IEEE 2014, 901-906.

25. Gogdare A.N., Doroudi A., Ghaseminejad M. A new method to mitigate voltage fluctuation of a fixed speed wind farm using DFIG wind turbine. In: 2012 Proceedings of 17 th Conference on Electrical Power Distribution. 2012; 1-6.

26. Belmokhtar K., Doumbia M.L., Agbossou K. Modelling and fuzzy logic control of DFIG based Wind Energy Conversion Systems. In: 2012 IEEE International Symposium on Industrial Electronics. IEEE 2012, 1888-1893.

27. Dscet.ac.in. [cited 2021 Dec 9]. Available from: https://dscet.ac.in/questionbank/aero/seventh-sem/ AE6009-Industrial-Aerodynamics.pdf.

28. Zhang X., Wang Y. Robust fuzzy control for doubly fed wind power systems with variable speed based on variable structure control technique. Math Probl Eng. 2014; 2014: 1-13. Available from: https:// www.hindawi.com/journals/mpe/2014/750101/

29. Ghane M., Nejad A.R., Blanke M., Gao Z., Moan T. Diagnostic monitoring of drivetrain in a $5 \mathrm{MW}$ spar-type floating wind turbine using Hilbert spectral analysis. Energy Procedia. 2017; 137: 204-213. Available from: https://orbit.dtu.dk/en/ publications/diagnostic-monitoring-of-drivetrainin-a-5-mw-spar-type-floating 